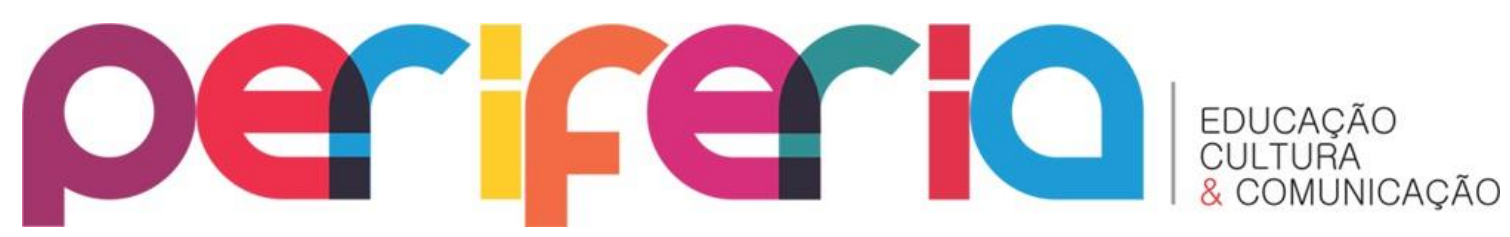

\title{
O PARFOR E AS PROJEÇÕES PARA A ESCOLA: A PROFISSIONALIZAÇÃO DOCENTE COMO ESTRATÉGIA REFORMISTA ${ }^{1}$
}

\author{
Rosana Maria de Souza Alves ${ }^{2}$ \\ Instituto Federal de Educação, Ciência e Tecnologia do Maranhão
}

\section{RESUMO}

O artigo aborda o Plano Nacional de Formação de Professores da Educação Básica Parfor como ponto de partida para pensar as reformas educacionais em curso no Brasil, problematizando as relações entre poder e conhecimento que atravessam as prescrições para a escola. Isto porque a criação do Parfor faz parte das ações de governo visando qualificar os professores que estão em exercício, com destaque para a habilitação daqueles que não possuem ensino superior. Considerando a emergência desse programa como uma construção histórica, esta análise tenciona problematizar alguns elementos que envolvem o processo de reconhecimento social da necessidade de profissionalização dos docentes, encarada como um mecanismo eficaz para promover mudanças na educação e em outros campos da vida social.

Palavras-chave: Reformas educacionais, Parfor, profissionalização docente.

\section{THE PARFOR AND PROJECTIONS FOR THE SCHOOL: THE PROFESSIONALIZATION AS REFORMIST STRATEGY \\ ABSTRACT}

This article addresses the National Plan for Teacher Training Basic Education - Parfor as a starting point for thinking about educational reform in Brazil, discussing the relationship between power and knowledge crossing prescriptions for school. This is because the creation of Parfor part of government actions aiming to qualify teachers who are in office, highlighting the empowerment of those without higher education. Given the emergence of this program as a historic building, this analysis intends to discuss some elements that involve the process of social recognition of the need for professionalization of teachers, viewed as an effective mechanism to promote changes in education and in other fields of social life.

Keywords: Education reform, Parfor, professionalization.

\footnotetext{
${ }^{1}$ Este artigo é parte da pesquisa de mestrado em andamento "Constituir-se profissional: sobre a experiência do Curso de Formação Docente (Parfor) no IFMA/Campus Codó (2010-2014)", vinculada ao Programa de Pós-graduação em Educação da UFRJ, sob a orientação do professor José Cláudio Sooma Silva.

${ }^{2}$ Pedagoga do IFMA e professora no programa Parfor. Atuou como assessora técnica do Ministério da Educação em Programas de Formação de Professores em Exercício. Mestranda em Educação na Universidade Federal do Rio de Janeiro. E-mail: rosanamaria@ifma.edu.br
} 


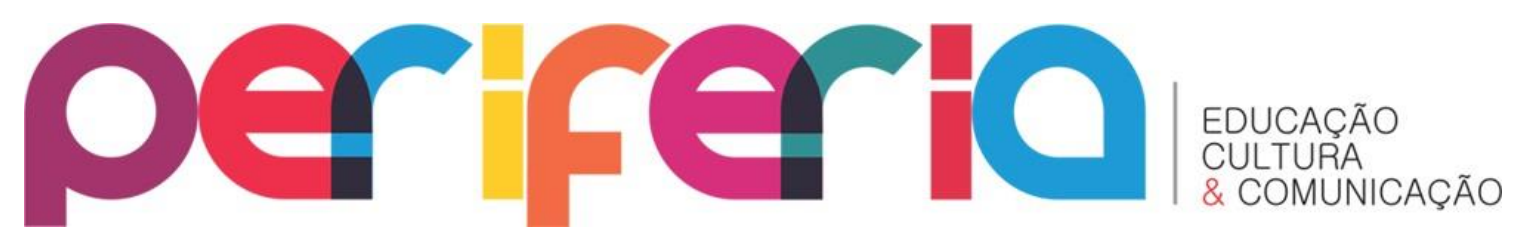

\section{INTRODUÇÃO}

De acordo com o Decreto no 6.755, de 29 de janeiro de 2009, fica instituída a Política Nacional de Formação de Profissionais do Magistério da Educação Básica, com a finalidade de organizar, em regime de colaboração entre a União, os estados, o Distrito Federal e os municípios, a formação inicial e continuada dos profissionais do magistério que atuam nas redes públicas de ensino. O Plano Nacional de Formação de Professores da Educação Básica - Parfor ${ }^{3}$, fruto dessa política, é regido pela Portaria Normativa no 9, de 30 de junho de 2009 e tem como objetivo induzir e fomentar a oferta de educação superior aos professores em exercício na rede pública de educação básica, para que estes obtenham a formação exigida pela Lei de Diretrizes e Bases da Educação Nacional - LDB e contribuam para a melhoria da qualidade da educação básica no país (CAPES/PARFOR, 2014).

Segundo a LDB (Lei no 9394/96), somente professores com nível superior podem atuar na educação básica, admitindo como formação mínima para a atuação na educação infantil e nas quatro primeiras séries do ensino fundamental a oferecida em nível médio na modalidade normal. Nessa perspectiva, a criação do Parfor como política pública, em sua dimensão prescritiva, faz parte das ações de governo visando qualificar os professores, com destaque para a habilitação daqueles que não possuem ensino superior.

É válido destacar que, antes desse programa, houve outras iniciativas governamentais para habilitação de professores que estavam em exercício nas primeiras séries do ensino fundamental e na educação infantil. Nesses casos, investiu-

\footnotetext{
${ }^{3}$ O Parfor Presencial é um programa nacional implantado pela Coordenação de Aperfeiçoamento de Pessoal de Nível Superior - CAPES em regime de colaboração com as secretarias de Educação dos estados, do Distrito Federal e dos municípios e com as instituições de ensino superior (IES). Os tipos de cursos oferecidos são: 1) licenciatura - para docentes ou tradutor/intérprete de Libras em exercício na rede pública da educação básica que não tenham formação superior ou que, mesmo tendo essa formação, se disponham a realizar curso de licenciatura na etapa/disciplina em que atuam em sala de aula; 2) segunda licenciatura - para professores que estejam em exercício há pelo menos três anos na rede pública de educação básica e que atuem em área distinta da sua formação inicial ou para profissionais que atuam como tradutor/intérprete de Libras; e 3) formação pedagógica - para docentes graduados não licenciados que se encontram no exercício da docência ou que atuem como tradutor/intérprete de Libras na rede pública da educação básica.
} 


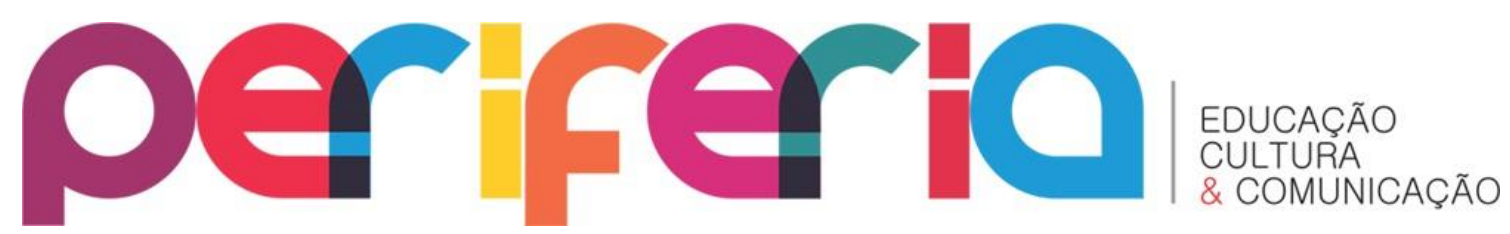

se na criação de cursos de nível médio na modalidade normal, tais como o Programa de Formação de Professores em Exercício - Proformação (implantado de 1999 a 2008 em 15 estados brasileiros) e o Programa de Formação de Professores em Exercício na Educação Infantil - Proinfantil (implantado de 2005 a 2011 em 18 estados), para citar alguns exemplos.

Criados em caráter emergencial, com base no argumento da necessidade de empreender reformas ${ }^{4}$ urgentes no sistema educacional brasileiro, esses programas partiram de esforços de governo visando corrigir o grave problema da admissão de professores não habilitados nas diferentes redes de ensino, notadamente a municipal, bem como tencionando combater, especificamente no caso do Parfor, a escassez de professores que atuam na educação básica no Brasil.

Isto porque, conforme levantamentos realizados pelo Instituto Nacional de Estudos e Pesquisas Educacionais Anísio Teixeira - INEP divulgados no ano de 2003, havia demanda de 235 mil professores no ensino médio e 476 mil nos anos finais do ensino fundamental, totalizando 711 mil docentes. Porém, foram formados 457 mil professores entre 1990 e 2001, o que não atendia sequer à demanda do segundo ciclo do ensino fundamental, permanecendo um déficit de 254 mil professores, com destaque para as áreas de Física e Química ${ }^{5}$. Esses índices foram considerados no relatório produzido pela Comissão Especial instituída pelo MEC para estudar medidas visando superar o déficit docente no Ensino Médio (RUIZ; RAMOS; HINGEL, 2007).

Embora tais políticas de formação docente tenham sido inicialmente associadas a um caráter emergencial, nota-se a durabilidade das racionalidades que legitimam

\footnotetext{
${ }^{4} \mathrm{O}$ termo reforma pode ser compreendido a partir de diferentes prismas. Neste artigo, por considerar a emergência do Parfor imersa num cenário de elaboração de políticas públicas amplamente influenciado pela criação do Plano de Desenvolvimento da Educação (PDE/2007), utilizo essa ideia de acordo com o que exprime a legislação educacional. Publicado pelo Ministério da Educação, esse documento aborda as razões, os princípios e os programas norteadores das mudanças preconizadas pelo Governo Federal, sendo recorrente a crença de que o investimento na formação de professores constitui-se em mecanismo eficaz para a superação do passado por meio da educação. A esse respeito, consultar Haddad (2008).

5 Informação disponível no site do Inep, no endereço eletrônico: http://portal.inep.gov.br/c/journal/view article content?groupld=10157\&articleld=15215\&ve. Acesso em: 29 ago. 2012.
} 


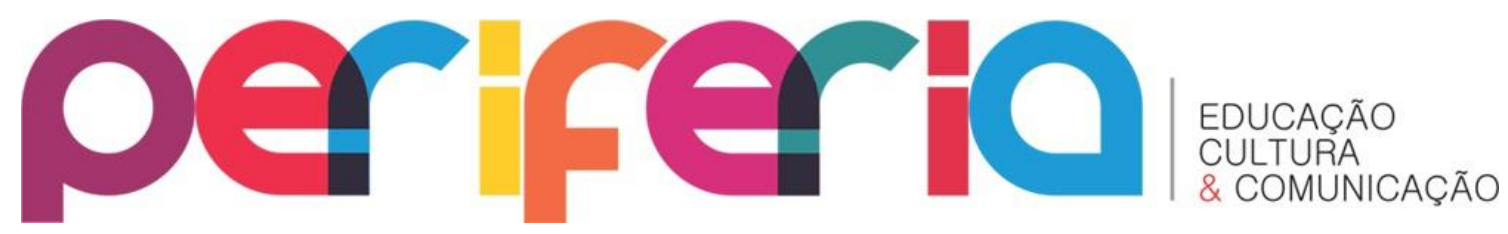

essas propostas. Conforme Bocchetti e Bueno (2012), a partir da LDB de 1996 houve uma profusão de políticas e cursos voltados à formação docente em território nacional. Estes, justificando-se também a partir da Resolução n 02/97 do Conselho Nacional de Educação - CNE, passaram a ser conhecidos como programas especiais de formação, destinados a "suprir a falta nas escolas de professores habilitados, em determinadas disciplinas e localidades, em caráter especial" (MEC, 1997). Para os autores, embora a criação desse formato de cursos devesse se encerrar ao final da década da educação (1997-2006), o modelo dos programas especiais foi retomado na Política Nacional de Formação Docente em 2009, conforme citado anteriormente.

O que parece particularmente interessante na construção dessas propostas, mais recentemente voltadas para deslocar a formação dos professores do nível médio para o nível superior, é que têm sido amplamente fundamentadas no discurso que afirma a necessidade de investimento na formação de professores como estratégia para empreender reformas profundas na educação e em outros âmbitos da vida social. Para tanto, defende-se que as políticas educacionais devem atrelar a necessidade de melhoria da educação básica à reelaboração dos programas de formação docente. Ou seja, compreende-se a necessidade de vincular melhor e alinhar os universos da formação inicial e do desenvolvimento profissional às orientações de políticas educativas para a educação básica, por um lado, e às do ensino superior, por outro (LESSARD, 2006, p. 204).

Essa prerrogativa está presente no PDE (2007) quando expressa a necessidade de superação de uma "falsa oposição" entre a educação básica e a educação superior, que, segundo o então ministro Fernando Haddad, gerou no Brasil a focalização de investimentos no primeiro nível, com ênfase no ensino fundamental, o que ocasionou a "falta de professores com licenciatura para exercer o magistério e alunos desmotivados pela insuficiência de oferta de ensino gratuito nas universidades públicas" (HADDAD, 2008, p. 8). Em virtude disso, o Governo Federal defende que, para reforçar a educação básica, é necessário o investimento na educação superior, com destaque para a formação de "bons" professores em número suficiente. 


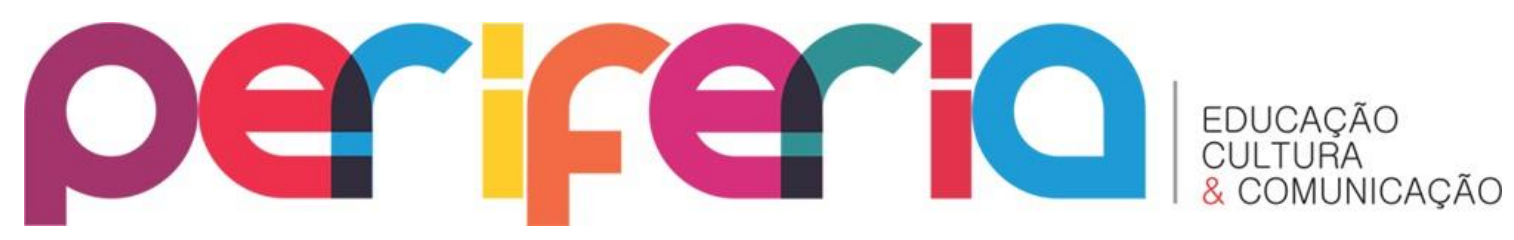

Para que isso ocorra, de acordo com o documento em questão, faz-se necessário superar esta e outras "falsas oposições" citadas, o que só pode ser alcançado quando houver uma visão sistêmica de educação, ou seja, quando os níveis educacionais forem tratados como uma unidade, da creche à pós-graduação, de maneira que a formação inicial e continuada do professor esteja voltada para a melhoria da qualidade da educação básica (e vice-versa).

Nesse movimento de busca por mudanças no sistema educacional brasileiro como um todo, cabe retomar o que expressa a LDB no 9.394/96 no que se refere aos requisitos de formação e exercício profissional docente. Isso porque é característica da lei a tendência de investimento na formação dos professores, considerados profissionais do ensino, a partir da "associação entre teorias e práticas, mediante estágios supervisionados e capacitação em serviço" (BRASIL, 1996, Art. 61). Com isso, a escola adquire status de espaço de formação contínua dos professores que, por não possuírem formação inicial realizada em instituição específica, ou por não terem o certificado que comprove a aquisição dos conhecimentos e habilidades necessários ao exercício do magistério, são considerados "leigos". Nessa perspectiva, a ausência de uma formação "adequada" e "certificada" é tida como um empecilho à atuação profissional desses sujeitos.

Embora essa ideia pareça algo consensual em tempos recentes, óbvia e/ou necessária, cabe desnaturalizar alguns elementos que envolvem o processo de reconhecimento social da necessidade de profissionalização dos docentes, por meio do acesso a uma formação em nível superior. A intenção deste artigo é elaborar uma possível compreensão da emergência dessas políticas como construções que, apesar de socialmente legitimadas, não são naturais, ou seja, são frutos de práticas sociais imersas em um campo de disputas relacionadas às demandas do período histórico em que se situam.

Adiante, ao debate acerca das demandas por melhorias na qualificação dos professores entrelaçadas às projeções voltadas para as instituições educacionais serão acrescidas contribuições de alguns pesquisadores que realizaram estudos históricos sobre 


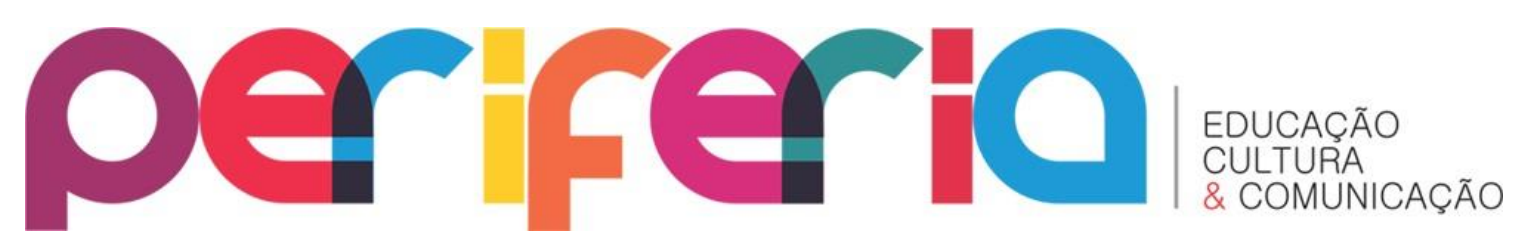

a profissão docente, buscando analisar suas potencialidades e limites para uma possível interpretação da emergência do Parfor no Brasil.

\section{INTERLOCUÇÕES TEÓRICAS SOBRE O PROCESSO DE PROFISSIONALIZAÇÃO DOCENTE}

Segundo Weber (2003), as profissões são abordadas sob diversos enfoques na literatura específica, havendo acordo quanto à impossibilidade de organizar os achados sob uma única teoria. Ciente da complexidade que envolve tal debate, a ideia é abordar uma das faces do problema, o processo de profissionalização de uma atividade desenvolvida no mundo do trabalho que passa a ter delimitados pelo Estado requerimentos de formação e de exercício, tal como ocorre na atualidade com a docência da educação básica (WEBER, 2003).

Ao analisar alguns aspectos relacionados à emergência de programas de formação de professores a partir dos anos 1990, com destaque para o Parfor, é possível identificar a vigência de uma variedade de correntes de pensamento pautadas em pesquisas envolvendo diferentes campos do saber (e inclusive dentro de um mesmo campo). Diante disso, o recorte aqui utilizado versa sobre as possíveis contribuições de estudos de história da profissão docente em seu potencial para acrescentar outros elementos ao debate.

Segundo Catani (2007), a produção de estudos históricos sobre a profissão docente no Brasil possui comparecimento recente e, embora sejam abundantes as pesquisas relacionadas a formação, instituições, saberes, atividades, organização da categoria, a expressão "história da profissão docente" é mais rara. Tal observação fazse importante na medida em que a autora defende que a mesma é unificadora das várias dimensões do exercício profissional do magistério, cuja concepção exige a análise simultânea e integrada dessas mesmas dimensões.

Em diálogo com António Nóvoa (1998), importante pesquisador que elaborou uma análise sócio-histórica da profissão docente em Portugal entre os séculos XVIII e XX, a autora chama a atenção para a dificuldade de encontrar trabalhos que articulem a problemática da história das ciências da educação à história da profissionalização dos professores em diferentes países ocidentais. Para o autor, 


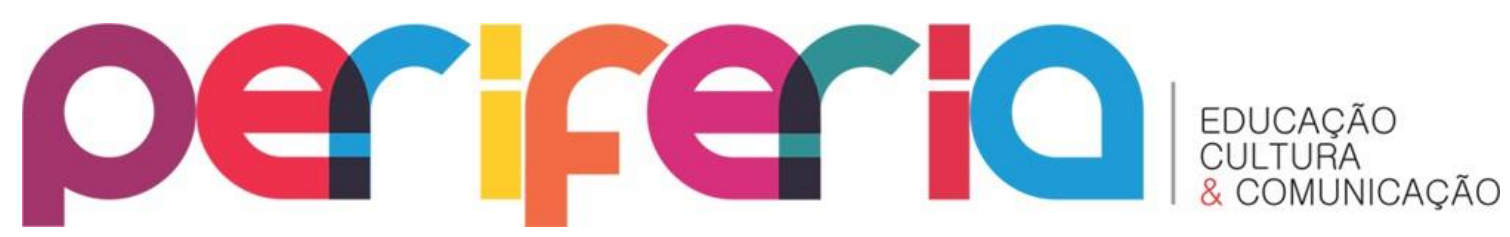

[...] no primeiro caso, privilegia-se frequentemente uma reflexão interna que permite estudar as questões epistemológicas do 'saber', mas pouco reveladora dos conflitos de 'poder' que estruturam a elaboração histórica das ciências da educação. No segundo, a análise é quase sempre orientada pelas preocupações ligadas ao estatuto econômico, à imagem social ou à identidade profissional dos professores, deixando de lado suas relações com o saber, principalmente com o saber pedagógico (NÓVOA, 1998, apud CATANI, 2007, p. 588).

Longe de pretender resolver essas questões, porém considerando o alerta dos autores supracitados para introduzir algumas reflexões referentes ao processo histórico de profissionalização docente no Brasil, o diálogo com Nóvoa apresenta-se frutífero, posto que, embora o autor elabore uma análise pautada na experiência de Portugal, acompanhando suas próprias palavras, esta apresenta grandes semelhanças se comparada aos diferentes países que compõem as sociedades ocidentais. Assim, sem negar as especificidades, o autor defende "o caráter transnacional da maioria das questões concernentes aos professores" (Ibidem, p. 586).

Nóvoa elaborou um modelo interpretativo que examinou o processo de profissionalização português, definido em torno de quatro etapas, ao longo das quais se configurou o estatuto social e econômico dos professores: 1) o exercício do ofício como ocupação principal; 2) a configuração de licença do Estado como suporte legal para o exercício da profissão; 3) a criação de instituições específicas voltadas para a formação docente; e 4) a constituição de associações profissionais de professores. Além disso, destaca a elaboração de um conjunto de conhecimentos e de técnicas, bem como de normas e de valores, destinados a nortear o exercício dessa atividade profissional durante o período analisado (NÓVOA, 1991, 1995).

Para ele, a profissionalização docente esteve intimamente ligada à constituição dos Estados nacionais modernos pelo movimento de secularização e de estatização do ensino, que imprimiu maior controle aos processos educativos. Apesar disso, pondera que os modelos escolares elaborados sob a tutela da Igreja prolongaram-se; contudo, 


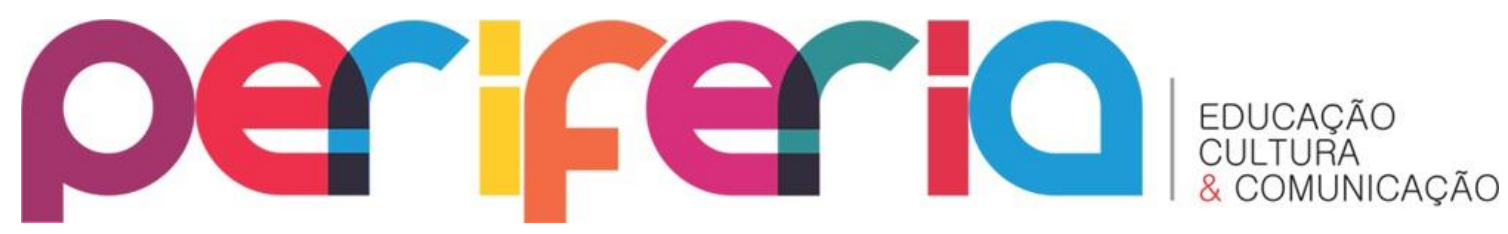

passaram a ser dinamizados por um corpo de professores recrutados pelas autoridades estatais.

Ancorado nos estudos de Julia (1981a), o pesquisador admite que as motivações, as normas e os valores originais da profissão continuaram vigentes, tendo "o modelo do professor permanecido muito próximo do modelo do padre" (JULIA, 1981a apud NÓVOA, 1995, p. 15). Apesar dessas permanências, segundo ele, uma mudança significativa delineou-se nesse período: se, enquanto mantida sob a tutela da Igreja, a função docente desenvolvia-se de forma subsidiária e não especializada, com a estatização o ensino foi, ao poucos, tornando-se ocupação principal, exercendo-se em tempo integral.

É importante frisar o alerta de que, embora os estudos nesse campo imputem a gênese da profissão docente à ação dos sistemas estatais de ensino, mais recentemente pesquisas apontam que, no início do século XVIII, havia uma diversidade de grupos que encaravam o ensino como ocupação principal. Contudo, Nóvoa chama atenção, como mudança significativa para o fato de que "a intervenção do Estado vai provocar uma homogeneização, bem como uma unificação e uma hierarquização à escala nacional de todos estes grupos" (NÓVOA, 1995, p. 16-17).

Outro fator relevante é a elaboração de um corpo de conhecimentos direcionados à educação da infância, considerada uma etapa da vida cuja intencionalidade educativa é permeada pela necessidade de governo da população, no contexto dos Estados nacionais. Emerge, nesse movimento, a pedagogia como ciência, constituída de um corpo de conhecimentos especificamente voltados à relação dos professores com os objetivos de ensino. Nessa perspectiva, de acordo com o autor, o aperfeiçoamento dos instrumentos e das técnicas pedagógicas, a introdução de novos métodos e o alargamento dos currículos escolares dificultaram o exercício do ofício como atividade secundária. Assim, o trabalho docente passou a diferenciar-se, tornando-se assunto de especialistas, que são chamados a consagrar-lhe mais tempo e energia (NÓVOA, 1995, p. 16). 


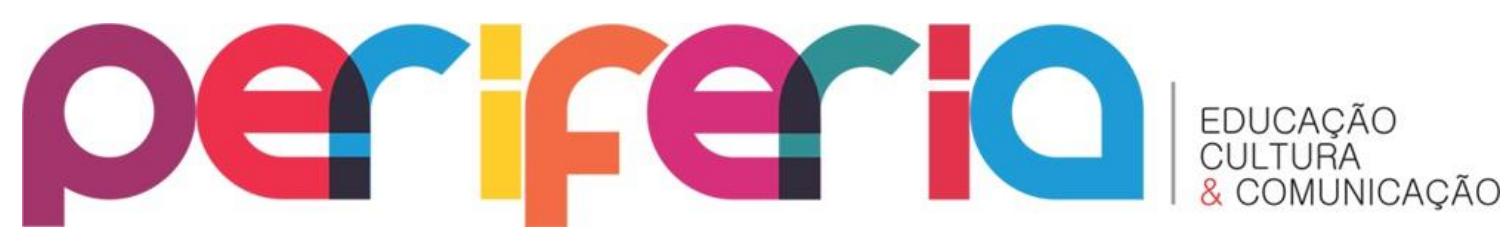

Além dessas questões, outro elemento passou a integrar as preocupações dos reformadores do século XVIII: a definição de regras uniformes de seleção e de nomeação dos professores, de maneira a "organizar" a diversidade que havia marcado o exercício das situações educativas, o que não se adequava às novas configurações político-sociais advindas da emergência dos Estados nacionais modernos. Nesse período, para os dirigentes era preciso "subtrair os docentes à influência das populações e dos notáveis locais e os considerar como um corpo do Estado" (NÓVOA, 1991, p. 121). Com isso, tem-se a criação de uma licença ou autorização para que os professores exerçam legalmente a atividade docente, a qual é concedida na sequência de um exame que pode ser requerido pelos sujeitos que preencham certo número de condições (habilitações, idade, comportamento moral etc.).

A elaboração dessa espécie de "autorização" é um momento decisivo do processo de profissionalização docente, uma vez que facilita a definição de um perfil de competências técnicas que servirá de base ao recrutamento dos professores e o delinear de uma carreira docente. Além disso, esse documento também contribui para a delimitação do campo profissional do ensino e para a atribuição ao professorado do direito exclusivo de intervenção nessa área, funcionando como a legitimação oficial da sua atividade, o que vai influenciar as dinâmicas de afirmação profissional e de reconhecimento social dos professores.

Outro fator importante para o processo de profissionalização docente, segundo esse modelo analítico, dá-se com a criação de instituições específicas de formação. De acordo com o pesquisador português, embora fosse um projeto antigo, a criação das Escolas Normais somente se realizou em pleno século XIX, graças à conjugação de interesses vários, nomeadamente do Estado e dos próprios professores. Para ele, "mais do que formar professores (a título individual), as escolas normais produzem a profissão docente (a nível colectivo), contribuindo para a socialização dos seus membros e para a génese de uma cultura profissional" (NÓVOA, 1995, p. 18).

Com relação aos interesses dos próprios professores, mais exigências de acesso ao exercício do ofício, possessão de um conjunto de conhecimentos especializados e 


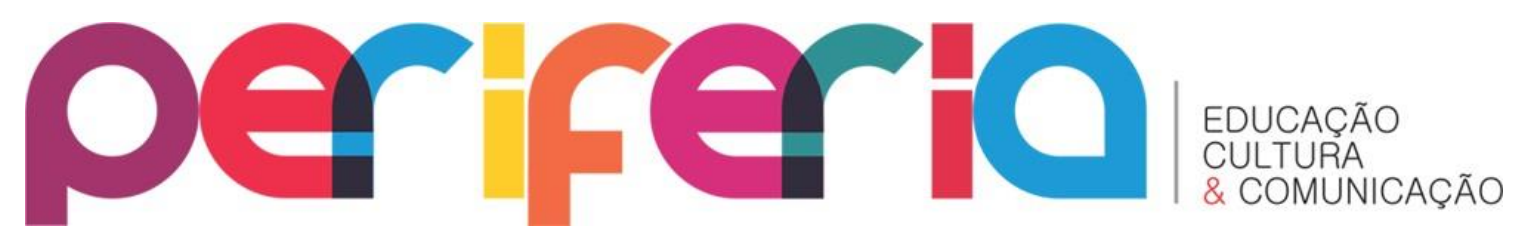

elevação do nível acadêmico com base na ideia de que realizam de um trabalho da mais alta importância social são algumas das reivindicações inscritas nas lutas associativas dos séculos XIX e XX. Nesses termos, a segunda metade do século XIX constitui-se em uma época-chave para compreender a ambiguidade do estatuto dos docentes, uma vez que, embora fosse reconhecida a importância social do trabalho dos professores, estando, nesse ponto, mais próximos dos médicos e advogados, o nível de renda colocava-os ao lado dos artesãos ou dos operários especializados (NÓVOA, 1991, p. 126-127). Nesse cenário, forjaram-se as lutas em busca de maior prestígio para a profissão, que provocaram reforço do sentimento de solidariedade interna ao corpo docente e, num certo sentido, a emergência de uma identidade profissional (NÓVOA, 1995, p. 19). Esse seria o outro momento do processo de profissionalização: a constituição de movimentos associativos em defesa dos interesses dos professores.

Nessa perspectiva, o modelo analítico de Nóvoa relaciona o processo de profissionalização docente à afirmação da escola como locus de atuação desses especialistas, cuja atividade passou a ser norteada por um conjunto de conhecimentos e de técnicas necessários ao exercício qualificado da profissão.

É importante ressaltar que o autor pondera que esse modelo de análise não deve ser tido como uma evolução linear, mas ser tomado como um percurso repleto de lutas, conflitos, hesitações e recuos. Isso porque o campo educativo é ocupado por inúmeros atores (Estado, Igreja, famílias etc.) que sentem a consolidação do corpo docente como uma ameaça aos seus interesses e projetos. Por outro lado, aponta que o próprio movimento associativo docente teve (e tem) uma história de poucos consensos e de muitas divisões, o que permite encarar o processo de profissionalização com um olhar atento às tensões que o atravessam.

Diante disso, Nóvoa defende que a compreensão contemporânea do exercício concreto da atividade dos professores implica uma visão multifacetada que revele toda a complexidade de seus elementos constituintes. Tais apontamentos contribuem tanto para a configuração dos aportes teórico-metodológicos deste estudo como favorecem 


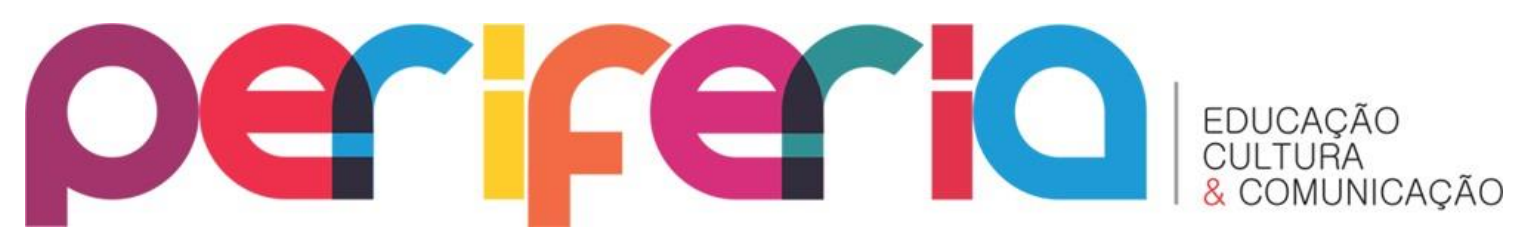

a definição das fronteiras da investigação acerca da emergência do Parfor, orientando os critérios de exclusão/inclusão e auxiliando a focalização do problema da profissionalização do magistério pela experiência do programa.

\section{A HISTÓRIA DA PROFISSÃO DOCENTE NO BRASIL: APROXIMAÇÕES EXPLORATÓRIAS}

Acerca desse aspecto, de antemão torna-se operatório sublinhar um alerta. A alusão, neste caso, é para a questão de que, sob hipótese alguma tenciono realizar um "resgate das origens da profissão docente" ou coisa do gênero. Antes de mais, ao incursionar de modo exploratório sobre algumas questões abordadas pelos autores que se debruçaram sobre o processo histórico de profissionalização docente no Brasil, pretendo iluminar apenas algumas possibilidades de análise das dimensões que perpassam a emergência do Parfor, reconhecendo que esse processo foi (e permanece sendo) atravessado por tensões, rupturas, disputas.

Isso porque, conforme as prescrições do programa já descritas, essa política tem o objetivo de melhorar a qualificação dos professores em exercício a partir do acesso a uma formação considerada adequada, diante dos requisitos de habilitação exigidos pela LDB № 9.394/96. Permeando as prescrições legais, encontram-se as projeções e as demandas sociais direcionadas à escolarização de crianças, cuja melhoria dos indicadores de qualidade é preconizada com base no investimento na formação docente em nível superior.

Tais elementos (função social da escola, formação de professores realizada em instituições específicas e suporte legal para o exercício da profissão) são aspectos que não podem ser negligenciados quando se analisa a "conformação" do corpo docente e a constituição de sua identidade profissional. Acrescente-se a isso a atividade organizada empreendida pelos próprios professores que, via movimentos associativos, buscam fazer valer seus interesses perante as formas de homogeneização e de controle governamental.

Retomando o modelo analítico de Nóvoa sobre fatores que integram o processo de profissionalização docente e que dialoga com aquilo que acabamos de 


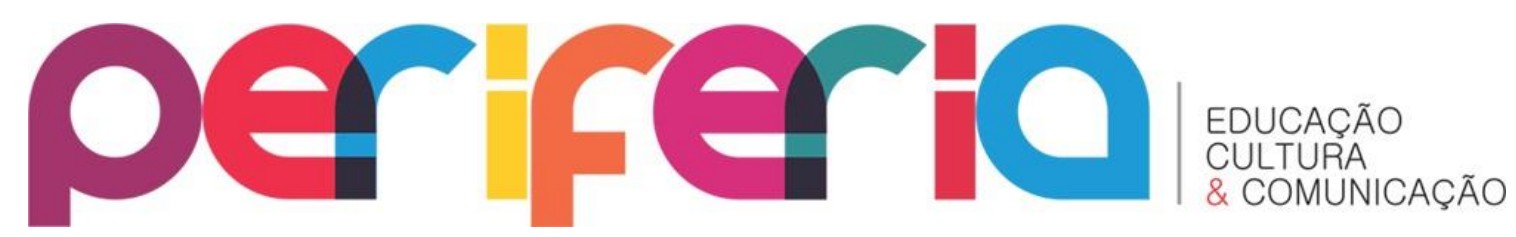

citar, cabe pensar o movimento em que o Estado brasileiro vai assumindo o controle da definição de regras uniformes de seleção e de nomeação dos professores, não sem reconhecer a atuação ativa dos profissionais via suas associações, talvez seja sugestivo - como movimento exploratório - incursionar sobre algumas práticas educativas ocorridas a partir do século XIX, que contribuíram para a emergência de instituições específicas direcionadas à formação desses profissionais.

Para nos ajudar a pensar o fenômeno descrito, Villela (2007), em diálogo com Nóvoa (1991), relaciona a emergência dos sistemas estatais brasileiros, no início do século XIX, a um controle governamental progressivo sobre a educação formal, com o objetivo de organizar um sistema de instrução primária no Brasil. Nesse período, observa-se o início de uma normatização, com a elaboração de documentações voltadas para ordenar o exercício do ofício docente, o que leva a um processo de "funcionarização" e contribui para a definição do estatuto socioprofissional dos professores. Soma-se a isso a criação das escolas normais provinciais, ainda no século XIX.

Surgidas a partir das décadas de 1830 e 1840, tais instituições tencionarão substituir o mestre-escola pelo professor primário, formado e preparado para o exercício da função. Esse processo, contudo, não se deu sem contradições, tensões, descontinuidades, tanto que no decurso do século XIX registrou-se um acentuado movimento de "abertura e fechamento" das escolas normais em território nacional: sintoma maior da disputa que caracterizou o fenômeno de institucionalização da profissão docente no Brasil.

A primeira escola normal a iniciar suas atividades foi a de Niterói, capital da Província do Rio de Janeiro, no ano de 1835. De acordo com a autora, essa instituição funcionou como um laboratório de práticas que deveriam ser tomadas como modelo para o restante do país, tendo em vista a grande influência de políticos locais no cenário nacional. Quanto ao currículo do curso, segundo a autora, somente aos poucos foi transformando-se num corpo de saberes característicos dessa formação: inicialmente, pouco diferia do currículo das escolas primárias, exceto pelo domínio do 


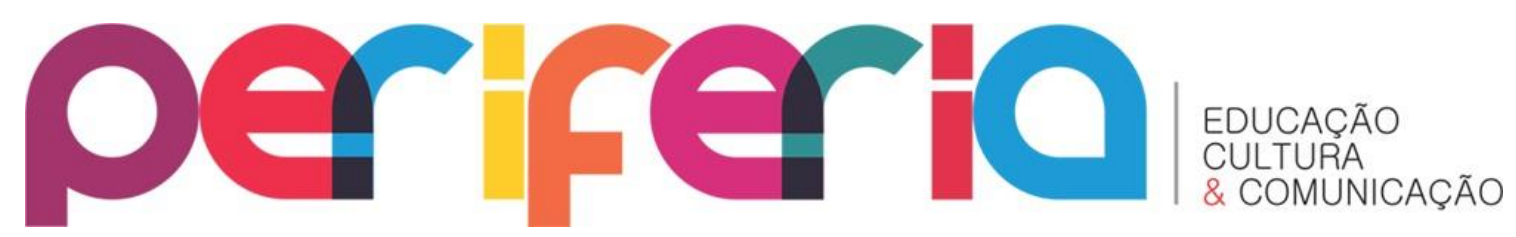

método lancasteriano ${ }^{6}$; posteriormente, com a Reforma de 1847, possibilitou uma formação diversificada para professores de ensino preliminar e de ensino médio e tornou o curso seriado, havendo também uma graduação de disciplinas em função do nível a que os futuros professores se destinavam a lecionar. Nesse momento, também é enxertada a disciplina denominada "Didática", assim como são incluídos estudos voltados às Ciências Físicas e Naturais.

Quanto às escolas normais criadas e reformadas em outras províncias, Villela aponta que revelam muitas aproximações com essa primeira experiência da Província do Rio de Janeiro, tendo passado por momentos de valorização e de instabilidade (pelo menos, até os anos 1860). Contudo, a partir da década de 1870 a formação de professores realizada nas escolas normais foi revalorizada, sendo essas mudanças motivadas pelas inúmeras transformações de ordem política, econômica e social, com destaque para o surto de urbanização e as demandas advindas desse processo, ampliando a procura por instrução.

Ainda acerca da discussão sobre o processo de criação de instituições específicas voltadas para a formação de professores como elemento-chave no processo de profissionalização no Brasil, cabe recorrer aos apontamentos elaborados por Faria Filho e Vidal (2000) quando abordam a criação do Ministério da Educação e Saúde (Mesp), nos anos 1930. Concebido como órgão central responsável pela elaboração de diretrizes gerais sobre a educação no Brasil, sua criação é tida como um acontecimento histórico relevante quando se pensa a questão da homogeneização de conteúdos, métodos, tempos e espaços escolares a serem implementados nos diferentes estabelecimentos de ensino brasileiros.

A criação desse ministério, de acordo com Gomes (2000), correspondeu a um processo de valorização e reconhecimento da necessidade de mudanças no campo educacional. Contudo, ele ressalta que "uma das grandes dificuldades para a

\footnotetext{
${ }^{6}$ Pautado nas ideias de Andrew Bell e Joseph Lancaster, o método mútuo ou lancasteriano, ao articular a ação educativa à atuação de alunos-monitores, um conjunto de sinais e comandos, a hierarquização dos saberes poderia instruir, conjuntamente, de mil a mil e quinhentos alunos. Acerca do método de ensino mútuo, dentre outros trabalhos, ver: BASTOS; FARIA FILHO, 1999; CARUSO; DUSSEL, 2003.
} 


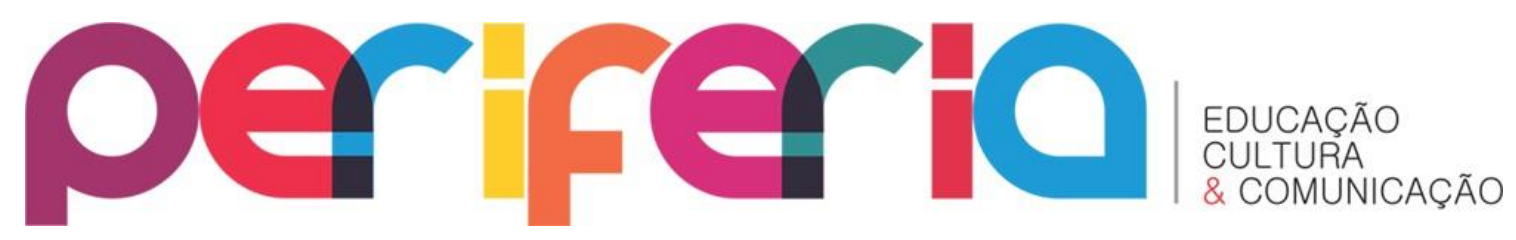

implementação e avaliação de políticas públicas nessa área foi, durante muito tempo, a ausência de dados estatísticos confiáveis sobre a situação do ensino no país" (GOMES, 2000, p. 405).

Frente a esse quadro, cresciam as críticas à orientação constitucional descentralizadora vigente até então. A criação do Mesp, em 1930, portanto, respondeu a uma demanda motivada por diferentes aspectos sociais e culturais. De acordo com Dias (2013), durante o governo de Getúlio Vargas foram amplas as iniciativas quanto ao processo de profissionalização do magistério; o estatuto social atribuído à profissão emergiu por meio de implicações de reformas no ensino secundário, da organização do trabalho docente nas escolas, das funções sociais e políticas atribuídas ao ensino e das concepções veiculadas acerca do magistério (DIAS, 2013, p. 111).

Para a autora, com a padronização do sistema educacional e a crescente centralização política, foram elaboradas medidas destinadas a viabilizar um maior controle do Estado sobre os agentes do ensino escolar: a partir de 1931 foi estruturado um novo modelo federal de regulamentação, fiscalização e orientação pedagógica para as escolas. Entre os requisitos para equiparação das instituições de ensino a ser obtida mediante inspeção federal, estava a inscrição dos docentes no Registro de Professores do Mesp.

A concessão de uma "licença" para ensinar passou a ocorrer mediante a comprovação dos requisitos exigidos por parte dos pretendentes a essa autorização, estando vinculada à habilitação dos professores em instituição própria - que, no caso do ensino secundário, deveria ser feita no ensino superior, pela Faculdade de Educação, Ciências e Letras, instituição também prevista pela reforma de 1931 (DIAS, 2013).

Sem adentrar as transformações legais, estruturais e curriculares que se sucederam, cabe apontar que entendemos a criação do Registro de Professores e a institucionalização da formação do professor secundário em cursos de nível superior como representativas da determinação do governo de instituir requisitos que 


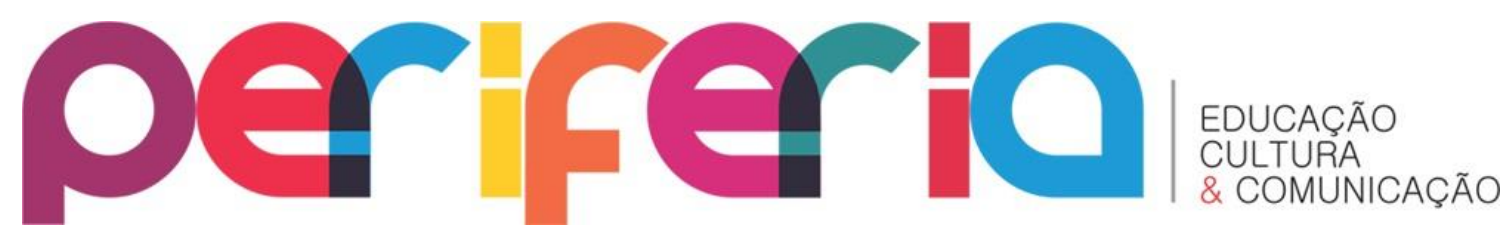

demarcavam quem poderia, ou não, integrar o campo de atuação profissional do magistério. Portanto, esses aspectos (o registro, a formação e a certificação) instituíram uma mudança na história do magistério de ensino secundário, até então exercido por profissionais de diversas áreas.

Ainda que essas medidas legais não tenham repercutido de forma impositiva nos diferentes estabelecimentos em que se exercia o ofício docente, posto que, conforme apontado anteriormente, até mesmo em tempos recentes existem diversos sujeitos que exercem a profissão sem cumprir as prescrições legais, concordamos com Dias (2013) em que essas medidas passaram a anunciar um estatuto profissional específico para o exercício do magistério no Brasil.

Consciente de suas limitações, esta breve incursão reportando ao período de criação do Mesp foi apenas para situar o leitor acerca do período histórico em que o governo brasileiro tomou para si, em caráter nacional, o controle da concessão de uma "autorização" para lecionar ou, de acordo com o modelo analítico de Nóvoa (1999), o momento de configuração de uma licença do Estado como "suporte legal para o exercício da profissão" (NÓVOA, 1999, p. 17).

Por outro lado, a reflexão sobre alguns elementos que envolveram o processo histórico de profissionalização docente no Brasil objetivou problematizar a construção de determinada "forma de ver" o fenômeno educacional como construção histórica. Refiro-me à crença na necessidade de que a formação de professores deva ser realizada em instituições específicas e em nível superior, ambas consideradas formas "adequadas" de exercício da profissão inclusive em tempos atuais.

Dito isso, para o estudo sobre a emergência Parfor, cabe considerar a conjugação desses fatores, embora seja necessário recorrer a outros elementos que vão além do âmbito prescritivo do problema, pois, para o aprofundamento desta análise, faz-se importante reconhecer o protagonismo dos professores cursistas que são, ao mesmo tempo, sujeitos e "objetos" das políticas públicas a que estamos nos referindo, o que será abordado em outras oportunidades e no decorrer da pesquisa que se encontra em andamento. 


\section{periferio}

\section{CONSIDERAÇÕES FINAIS}

Direcionando novamente as lentes para o Parfor, compreendendo-o como um acontecimento histórico cuja emergência relaciona-se às circunstâncias envoltas no tempo, a argumentação desenvolvida até aqui tomou sua elaboração como uma estratégia de intervenção governamental. Esse mecanismo utiliza a qualificação do professor para empreender reformas no campo educacional e na sociedade como um todo afinadas às necessidades e possibilidades do período histórico em que está imerso.

Sendo um meio para atingir esse fim, o Parfor carrega consigo a busca por uma formação docente mais adequada às propaladas "demandas da contemporaneidade", ideário que perpassa a promulgação de sucessivas medidas legais, tais como a LDB $n$ 으 9.394/96, que apregoa novos requisitos de formação e de exercício para a atividade do magistério, além de novas exigências quanto à habilitação mínima para atuar. Tem-se aí, portanto, pelo menos dois aspectos que perpassam a profissionalização dos professores: a formação específica e a licença para ensinar.

A partir das leituras até aqui realizadas e de posse das ponderações acima tecidas, penso ser possível delimitar a relevância do estudo acerca dos possíveis pressupostos, efeitos e estratégias adotadas para a criação e implementação de políticas como o Parfor, tendo em vista sua ênfase no tocante ao investimento público para a melhoria dos índices de desempenho do sistema educacional brasileiro como um todo.

Nessa perspectiva, pensar os diversos elementos que atuam na composição dessa lógica e chamar a atenção para a ideia de que isso não é exclusivo dos nossos dias pode ser um caminho para compreender, em diálogo com Nóvoa (1999), os discursos que projetam múltiplas e variadas missões aos professores na construção permanente - de uma "sociedade do futuro", visto que consideramos o processo de profissionalização algo complexo e em movimento, que perpassa a escola e suas interlocuções com as ações de governo; as projeções sociais que marcam as demandas 


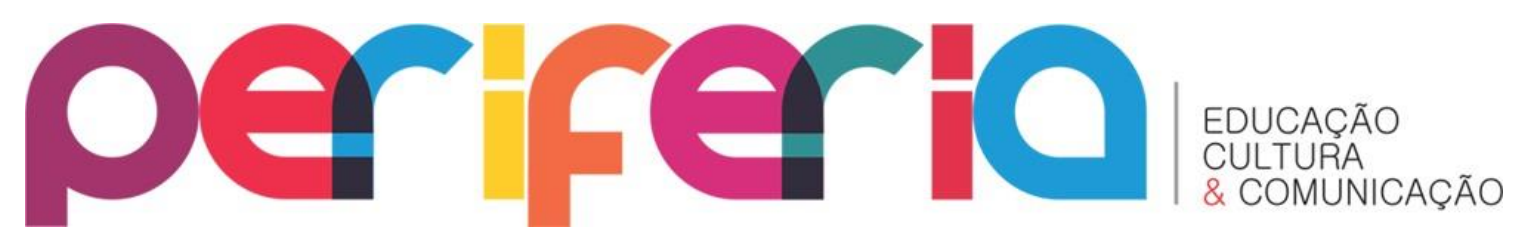

por escolarização e que influenciam a formação e o exercício da atividade docente; o controle do governo, por meio da legislação, quanto à licença para ensinar; os movimentos associativos que denunciam condições precárias de exercício da função e reivindicam melhorias etc.

Quando pensamos as articulações entre esses diferentes fatores, emerge o desafio permanente quanto às definições das funções sociais da escola e das suas interlocuções com a elaboração de políticas educacionais, especialmente as de formação de professores, uma vez que as prescrições educacionais são alvo de disputas que envolvem as ações de governo, as postulações de diferentes grupos sociais, as reivindicações por parte dos próprios sujeitos professores quanto às suas condições de trabalho nas escolas, as necessidades dos alunos, as formas de gestão dos sistemas de ensino, a participação das famílias etc. Todas essas dimensões, somadas àquelas já citadas, conferem enorme complexidade à compreensão do fenômeno educacional e problematizam a busca por reduzi-lo a fatores exclusivamente de ordem econômica, política, epistemológica etc.

Essas questões, portanto, atravessam o processo de profissionalização docente e as políticas públicas criadas com esse fim, não sendo possível nos aprofundarmos em todos eles. O recorte aqui realizado visa contribuir para alcançar um entendimento melhor sobre o presente, examinando as condições históricas que atravessam as crenças e práticas dos sujeitos sociais, entendidas como um campo de disputas, bem como possibilita questionar os sentidos únicos atribuídos a certos fenômenos como, por exemplo, a afirmação da escola como espaço educativo hegemônico diante de outras formas de socialização, o currículo e os métodos de ensino, os requisitos de qualificação do professor e a licença para ensinar.

\section{REFERÊNCIAS}

BASTOS, M. H. C.; FARIA FILHO, L. M. (orgs.). A escola elementar no século XIX: o método monitorial/mútuo. Passo Fundo: Ediupf, 1999.

BOCCHETTI, A.; BUENO, B. O. Um professor (sempre) a formar: o governo das subjetividades docentes em programas especiais de formação. Currículo sem Fronteiras, v. 12, no 2, p. 376-392, maio/ago. 2012. p. 376-392. 


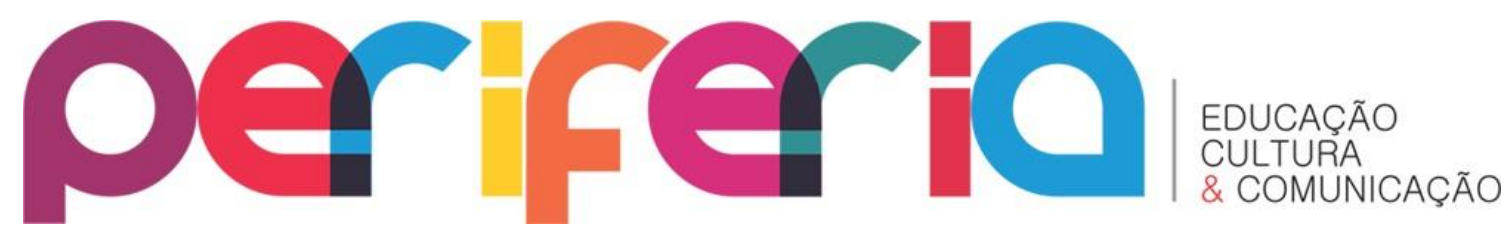

BRASIL. Lei $\mathrm{n}$ 9 9.394, de 20 de dezembro de 1996. Estabelece as diretrizes e bases da educação nacional. Diário Oficial da União, Brasília, 23 dez. 1996.

BRASIL. Decreto no 6.755, de 29 de janeiro de 2009. Institui a Política Nacional de Formação de Profissionais do Magistério da Educação Básica, disciplina a atuação da Coordenação de Aperfeiçoamento de Pessoal de Nível Superior - Capes no fomento a programas de formação inicial e continuada e dá outras providências. Diário Oficial da União, Brasília, 30 jan. 2009.

BRASIL. Ministério da Educação. Portaria Normativa no 9, de 30 de junho de 2009. Institui o Plano Nacional de Formação dos Professores da Educação Básica. Diário Oficial da União, Brasília, 1 jul. 2009a.

CAPES. Plano Nacional de Formação de Professores da Educação Básica - Parfor. Site da Capes. Disponível em: http://www.capes.gov.br/educacao-basica/parfor. Acesso em 11 jul. 2014.

CATANI, D. B. Estudos de história da profissão docente. In: LOPES, E.; FARIA FILHO, L.; VEIGA, C. (orgs.). 500 anos de educação no Brasil. Belo Horizonte: Autêntica, 2000.

DIAS, Amália. Apostolado cívico: a função social do magistério de ensino secundário (1931-1942). Revista Contemporânea de Educação, v. 8, no 15, jan./jul. 2013. p 111132.

DUCEL, I.; CARUSO, M. A invenção da sala de aula: uma genealogia das formas de ensinar. São Paulo: Moderna, 2003.

FARIA FILHO, L. M.; VIDAL, D. G. Os tempos e os espaços escolares no processo de institucionalização da escola primária no Brasil. Revista Brasileira de Educação, no 14 , maio/ago. 2000. p. 19-34.

GOMES, A. C. A escola republicana: entre luzes e sombras. In: GOMES, A.; PANDOLFI, D. C.; ALBERTI, V. (coord.). A república no Brasil. Rio de Janeiro: Nova Fronteira/CPDOC, 2002.

HADDAD, Fernando. Plano de Desenvolvimento da Educação: razões, princípios e programas. Brasília: Ministério da Educação, 2008.

JULIA, Dominique (198 lu). "La naissance du corps professoral". Actes de la Recherche en Sciences Sociales, 39, pp. 71-86 In: NÓVOA, A. O Passado e o Presente dos Professores In: Nóvoa, António (org). Profissão Professor. 2a Ed. Porto: Porto Editora, 1995.

LESSARD, C. A universidade e a formação profissional dos docentes: novos questionamentos. Educ. Soc., Campinas, v. 27, no 94, p. 201-227, jan./abr. 2006. p. 201-227.

MINISTÉRIO DA EDUCAÇÃO. CNE/CEB. Resolução no 2, de 26 de junho de 1997. Dispõe sobre os programas especiais de formação pedagógica de docentes para as disciplinas do currículo do ensino fundamental, do ensino médio e da educação profissional em nível médio. Diário Oficial da União, Brasília, 27 jun. 1997.

NÓVOA, A. Historie et comparaision (essai sur I' education). Lisboa: Educa, 1998. In: CATANI, D. B. Estudos de história da profissão docente. In: LOPES, E.; FARIA FILHO, L.; VEIGA, C. (orgs.). 500 anos de educação no Brasil. Belo Horizonte: Autêntica, 2000. 


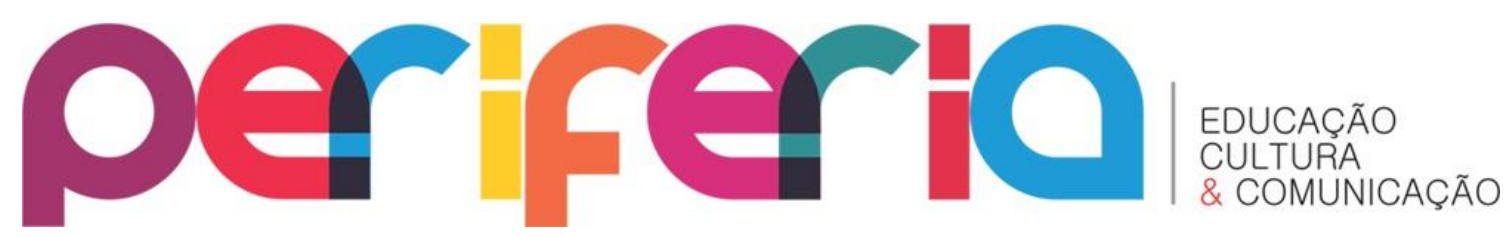

. A. O Passado e o Presente dos Professores In: Nóvoa, António (org). Profissão Professor. 2a Ed. Porto: Porto Editora, 1995.

Os professores na virada do milênio: do excesso dos discursos à pobreza das práticas. Educação e Pesquisa, São Paulo, v. 25, n. 1, p. 11-20, jan./jun. 1999. p. 11-20.

- Para o estudo sócio-histórico da gênese e desenvolvimento da profissão docente. Teoria \& Educação, n. 4, 1991. p. 109-137.

RUIZ, A. I.; RAMOS, M. N.; HINGEL, M. Escassez de professores no ensino médio: propostas estruturais e emergenciais. (Relatório técnico). Brasília: MEC/CNE/CEB, 2007. Disponível em: http://portal.mec.gov.br/cne/arquivos/pdf/escassez1.pdf. Acesso em: maio 2012.

VINCENT, G.; LAHINE, B.; THIN, D. Sobre a história e a teoria da forma escolar. Educação em Revista, Belo Horizonte, n. 33, p. 7-47, jun. 2001. p. 7-47.

VILLELA, H. de O. S. O mestre-escola e a professora. In: LOPES, E.; FARIA FILHO, L.; VEIGA, C. (orgs.). 500 anos de educação no Brasil. Belo Horizonte: Autêntica, 2000.

WEBER, Silke. Profissionalização docente e políticas públicas no Brasil. Educ. Soc., v. 24, no 85, p. 1.125-1.154, dez. 2003. p. 1125-1154. 